\title{
Concrete Fictions and Hegemonic Methodologies: Doing Policy Research in Government
}

\author{
William Mcallister \\ City University of New York
}

\begin{abstract}
Faced with having to justify programs to offices of management and budget, government agencies generate numbers which describe expected program impacts. But the assumptions or data on which these numbers are based are frequently suspect, as is the utility of relying on counts and modeling techniques for evaluating the achievement of program aims. The result is that agencies often create "concrete fictions," hard numbers with feet of (soft) clay. Offices of management and budget are able to make their methodology "hegemonic" because agencies usually have to secure their approval to get funding. But imposing this methodology encourages agencies to use research staffs more to defend against the budget office than to help create effective programs, creates differences between the expectations of government and the public, and fosters the overrepresentation of particular interests.
\end{abstract}

Oxymorons come easily in government policy research. Indeed, some might think just the combination of the word "government" with the words "policy research" creates an oxymoron, caused by the conflict between the researcher's presumption of discovering how the world works and the need of government officials to construct reality to suit their goals.

One oxymoron that describes some policy research in government is the notion of "concrete fictions." Briefly, these are numbers that represent expected program effects and that result from nuanced calculations based on weak evidence and empirically unsubstantiated assumptions. While working at New York City's social welfare agency, the Human Resources Administration (HRA), I observed the creation of concrete fictions. In

I thank Andrew Dunham and James Morone for their suggestions.

Journal of Health Politics, Policy and Law. Vol. 19. No. 1, Spring 1994. Copyright $(1994$ by Duke University. 
the next section, I discuss what concrete fictions are and how they work, using the example of homeless policy planning.

HRA did not create concrete fictions as an analytic exercise. They were specific responses to the mayor's Office of Management and Budget (OMB). The institutional position of OMB relative to other government agencies, combined with OMB's characteristic methodology, leads agencies, like HRA, to create concrete fictions.' Later in this paper I explain how OMB's methodology becomes "hegemonic" as it is consciously or effectively imposed on other agencies.

But this methodology is problematic and impacts government research, policymaking, the expectations of the public and of the government, and the representation of different interests in the decision-making process. I close the paper with a discussion of these issues.

\section{Concrete Fictions}

Often, new government programs or changes to existing ones are put into place with little, if any, idea as to what the effects will be. There are several reasons for this. Programs are designed as if the situation is static, while the world is changing very rapidly; prior experience is of limited use since the situation is almost never directly and specifically analogous to other circumstances; there usually is not enough time to carry out the necessary research; programs take time to implement as the context keeps changing; and implementation has effects that differ from what was designed. Even when these circumstances do not obtain, the world is sufficiently complex that important unintended and unanticipated consequences are likely to occur.

One response to this dilemma would be for officials to say something like "We're instituting this program in the hope that it reduces or solves problem $x$. Here's why we think it may have this result. But we don't have any good evidence this will happen. We really cannot say whether or not this outcome will occur."

The last two sentences are unlikely to be uttered, publicly or even inside government. Instead, analysts create concrete fictions-estimates of program effects expressed in the form of numbers that result from seemingly real and very detailed calculations of program impact but that are con-

1. This is not the only reason why agencies create concrete fictions. For example, governments may need them to respond politically to those outside government who want to limit government's scope. 
structed on dubious or unsubstantiated data and assumptions. What makes the estimates concrete is that they take the form of a number-hard, precise and, in modern government, something a computer can mull overand the calculations leading to the number are very detailed; the more detailed, the better. What makes them fiction is that the data underlying the calculations are frequently guesses, sometimes ill-informed guesses, and most, if not all, of the necessary assumptions can rarely be empirically grounded. ${ }^{2}$

An example is in order. Trying to deal with New York City's homeless family problem, the Human Resources Administration devised a five-year plan. One feature was a group of programs to prevent families from needing to use the city's homeless shelters. Programs included identifying families at risk of losing their housing and taking steps to prevent this from occurring by, for example, paying rent to prevent eviction or arranging for legal counsel in housing court.

Table 1 reports calculations carried out for the 1989 progress report on the five-year plan for homeless families (Grinker 1989). It shows the end of fiscal year (FY) impact of prevention programs on the family shelter population. The number in each cell reports or estimates the end-of-fiscalyear impact of each program above the FY 1987 effect. (Impacts were expressed relative to 1987 for political reasons.) Thus, the number 16 in the column headed June 1990 means there were expected to be sixteen fewer families in city shelters on 30 June 1990 because of changes in the eviction prevention programs than there would have been on that date without these changes. ${ }^{3}$ I will describe how this number was created.

Eviction prevention programs consisted of two separate efforts that tried to help families avoid being evicted by their landlords; these programs were the Housing Court Liaison (HCL) and the Legal Aid Eviction Assistance Demonstration Projects (Legal Aid). HCL paid rent to prevent eviction for nonpayment, and the Legal Aid program provided legal counseling in housing court for families in danger of losing tenancy.

2. The data problems may be particularly acute in social welfare research, especially when studies rely on those who set up and nun programs to supply numerical information. Because these people are usually not interested in research or planning and because they fear the accountability that numbers portend, "program people" tend not to count very well.

3. As the reader follows this description of how a concrete fiction was created, she or he may well ask if it is worth all this effort to measure such meager effects. However, just because the model was doubtful does not mean that implementing the programs would be a waste of time. The estimations could be wrong or there might be other benefits not calculated here and, perhaps, not calculable in an arithmetic way. For examples of the benefits of these programs that $I$ do not report, see New York State Department of Social Services 1990. 
Table 1 Impact of Preventive Programs on New York City's Homeless Family Shelter Population at the End of the Fiscal Year, 1988-1992

\begin{tabular}{lccccc}
\hline & \multicolumn{5}{c}{ Reduction in Number of Families } \\
\cline { 2 - 6 } Program & June & June & June & June & June \\
\hline City-Wide Expansion of Housing Alert & 9 & 34 & 113 & 130 & 137 \\
Eviction Prevention & 5 & 12 & 16 & 19 & 20 \\
Apartment Sharing & 0 & 0 & 73 & 88 & 95 \\
Permanent Housing Waiting List & 0 & 0 & 0 & 0 & 78 \\
$\quad$ Total Decrease in Shelter Size & 14 & 46 & 202 & 237 & 330 \\
\hline
\end{tabular}

Source. Human Resources Administration, City of New York.

The account of how the calculations were made is a little tedious. But that's the point: the more numbers used and the more nuanced the estimation procedure, the more "real" expected program effects seem to be. ${ }^{4}$ Most important, effects are defined as lowering the city shelter population because that translates into lower direct costs for the city-a primary OMB aim. And convincing the budget office to open the city's wallet a little wider is what this exercise is mostly about.

There are three parts to the calculation. The first two estimate the number of families not entering shelters over a year because of rent payments in housing court (HCL) or because of legal counseling (Legal Aid). The third estimates the impact on the shelter population at the end of the fiscal year of those families not entering the shelters.

\section{Housing Court Liaison}

According to program figures, HCL paid rent for 2,789 families in FY 1989,605 above the FY 1987 level of 2,184. Since there was no evidence peculiar to this program suggesting the rate at which families served were prevented from becoming homeless, analysts used the rate suggested by a study of another program which had a related, though different, population. This study suggested 2 percent of families served would have entered city shelters. Thus, since $605 \cdot 0.02=12$, the number of families not

4. While the description can get tedious, these calculations use very simple arithmetic and are not very complicated compared to estimations of effects in other policy areas. 
entering the homeless system because of the HCL program for each fiscal year was deemed to be 12 .

This calculation was relatively straightforward. But the accuracy of the family count is unknown, and relying on a study of a different population for the crucial percentage is a major assumption whose error could not be known.

\section{Legal Aid Projects}

To figure out the success of Legal Aid programs, HRA estimated the following equation:

$$
N=F \cdot S \cdot H
$$

where

$N=$ number of families prevented from entering shelters,

$F=$ total number of families helped by the Legal Aid programs,

$S=$ proportion of families Legal Aid successfully helped avoid eviction, and

$\boldsymbol{H}=$ proportion successfully helped who would have entered shelters.

The first step was to estimate $F$, the total number of families the programs would help. Over a sixteen-month period ending on 31 July 1988, the three demonstration programs handled 1,691 cases, according to HRA counts. This is 105.7 per month or 1,268 per year, which was projected onto 1990.

This measurement was relatively easy, as it required a count of previous behavior and a simple inference. But for political reasons and due to the nature of the activity being counted, HRA counts tended to be unreliable. An evaluation of these programs by the New York State Department of Social Services (1990), relying on counts from program operators, showed a much higher case load. And whether such a simple projection is justified is an issue worth raising.

The next step was to estimate the proportion of families successfully served, that is, whose tenancy was maintained. There were two relevant measures of proportion. The first counted families who were evicted but who successfully fought the eviction in court. An HRA study estimated that these constituted 12 percent of the total number of families handled by Legal Aid..$^{5}$ In order to prevent double counting with an overlapping

5. More specifically, this was the percentage successfully helped by the Brooklyn Legal Aid project, one of three such projects. Because changes in 1989 made all three projects conform to the Brooklyn project, estimations relied on statistics from Brooklyn. 
program, this number was reduced by 6 percent, the percentage arbitrarily expected to be handled by that other program. However, there was no evidence on the extent to which programs overlapped or on how long "successfully" aided families stayed housed.

The second measure of proportion covered evicted families who used Legal Aid help to settle out of court. But this does not mean that families were permanently established in their apartments. In general, the settlement was a temporary arrangement. Such families were estimated to be 50 percent of the total caseload. But since there was no way to know how long "temporary" would be, it was arbitrarily decided that only a quarter would be able to stay in their apartments long enough for their court settlement to be counted successful. Thus, 50 percent was reduced to 12.5 percent. Obviously, this number has little behind it but arbitrary judgments. To calculate the estimated success rate of the Legal Aid programs over and above FY 1987, we sum the two proportions: $0.06+$ $0.125=0.185$.

The third step was to estimate the proportion of successfully helped cases that would otherwise have entered the shelters. To do this, the number of evicted public assistance families entering the shelters was divided by the total number of public assistance families evicted in a year: 1,267 / $12,500=0.101$. The first number was derived from a rate estimated in a New York University study that more or less met academic survey standards; the second was from HRA records. Thus, these estimates were relatively stronger than others in this task, though HRA records are notoriously unreliable.

We then multiply the three estimates,

$$
\begin{aligned}
N & =1268 \cdot 0.185 \cdot 0.101 \\
& =24 .
\end{aligned}
$$

This product is added to the HCL program number, estimated earlier, yielding a total of 36 families prevented from needing to use the city shelters in 1990 due to the city's eviction prevention programs.

\section{Shelter Population Impact}

A final step remains. Preventing 36 families from entering the shelters over the course of a year does not mean they all would have remained sheltered by the last day of the fiscal year (the day of reckoning in Table 1). Some might enter in October and stay a week or two months; others might enter in July and stay the year. So, the effect on the population at the end 
of the fiscal year has to be calculated. To do this, the following formula was estimated:

$$
I=(F \cdot((S S \cdot M S)+L S))+E(F P \cdot L S \cdot E R),
$$

where

$$
I=\text { impact on end of fiscal year census, }
$$

$F=$ number of families prevented from entering shelters in current fiscal year,

$S S=$ percentage of families staying less than one year among new entrants,

$M S=$ mean length of stay for families staying less than one year,

$L S=$ percentage of families remaining in shelter one year or longer among new entrants,

$F P=$ number of families prevented from entering shelters in a previous fiscal year, and

$E R=$ exit rate for families sheltered more than one year.

Earlier, I showed how HRA estimated the number of families prevented from entering shelters. To estimate the rates at which families left the shelters, an HRA study examined the shelter history of a sample of families entering shelters over one month. This study provided estimates of the proportion of entering families that leave every 30 days, up to 270 days. Because of time limitations and poor data quality, direct estimates for more than nine months were not possible. Since estimates for 360 days were required, estimates for the final three months were extrapolated from the previous nine. The results showed that 74.6 percent of families left within a year, that is, 25.4 percent remained more than a year.

HRA also relied on this study to estimate the mean length of stay for new entrants leaving the shelters within a year ("short-term stayers"). The equation used was

where

$$
M=(N P \cdot D) / N,
$$

$M=$ highest possible mean number of days in shelters,

$N P=$ number in sample exiting per cumulated 30 -day period,

$D=$ number of days in cumulated 30 -day periods, and

$N=$ total sample size

The result of this calculation was 87.5 days, or 24.3 percent of a year.

As the study generating these estimates was carried out on the population of interest, with data better than usually available and with attention to data problems, the numbers for the first nine months are more reli- 
able than other estimates reported in this paper. Even so, the monthly error terms get large, and the need to extrapolate for the last three months introduces unknown and unknowable error into the calculations.

The final number to be estimated was the rate at which families sheltered at least one year would remain to the end of a second, third, or subsequent years. The estimates for the exit rates were as follows: Remaining to the end of a second year-34 percent; to the end of a third17 percent; to the end of a fourth -2 percent; to the end of a fifth- 0 percent. The study that generated the estimates was done well, but of necessity used data several years old (in a continuously changing system) and known to contain severe errors.

We now have estimates for all the terms in the equation calculating the impact of eviction prevention programs on the shelter population:

$$
I=(F C \cdot((S S \cdot M S)+L S))+E(F P \cdot L S \cdot E R)) .
$$

For FY 1990 this computes as

$$
\begin{aligned}
I & =((36 \cdot((0.746 \cdot 0.243)+0.254))+((6 \cdot 0.254 \cdot 0.34) \\
& =16 .
\end{aligned}
$$

That is, on 30 June 1990 , the city shelters were expected to house 16 fewer families because of these programs.

Thus is born a concrete fiction. The calculations are simple arithmetic and the model is not complicated. It would not be hard to create more sophisticated and impenetrable concrete fictions. But this example displays the procedure's essential features and problems. The calculations are mathematical and try to be nuanced. The data, however, have problems that undermine both the arithmetic and the would-be realism of the nuances: either their reliability is unknown (in a technical sense) or they do not measure the thing of most interest. And the needed assumptions are either completely arbitrary or their empirical basis is very limited.

Plausibly changing assumptions or the data are not hard to do. The New York State Department of Social Services (NYSDSS 1990) also estimated the impact of the Legal Aid programs on the number of families entering shelters. By relying on Legal Aid's estimate of the number of families served (instead of the HRA study used here) and by estimating differently the number of evicted families who were sheltered, NYSDSS estimated the Legal Aid programs would prevent 432 families from entering shelters over the course of a year, instead of the 24 estimated by HRA. 


\section{The Origins of Concrote Fictions}

Why are concrete fictions created? The answer I propose has two parts, one institutional, the other methodological. Both center on OMB.

The institutional part of the answer concerns the relationship between $\mathrm{OMB}$ and other city agencies. The analogy that comes to mind is the relationship between Wall Street investment banks and private corporations: the former's control over money the latter needs makes corporate decision making responsive to the concerns of investment banks. The basic role of OMB in New York City government is no different, that is, it enhances the mayor's control over agency spending throughout government. ${ }^{6}$ As such, OMB has an institutional predisposition to say no to funding requests, especially for new, unproven programs. And since, in general, an agency will be funded for programs only if it can convince OMB to change its implicit (and sometimes explicit) no to a yes, it must be able to respond to OMB. This response is most effective when done on OMB's terms, that is, by using OMB's methodology.

Life at OMB centers on numbers. Obviously, this is largely due to OMB's mission to budget, which necessarily involves numbers. Further, OMB currently is populated by people skilled in the principles and techniques of accounting, finance, and economics. If they are not accountants, they are, increasingly, people trained in public administration programs that are modeled after business administration schools and their emphasis on instilling these principles and techniques. In particular, formal modeling techniques, with their reliance on mathematics and the would-be sophisticated computer-driven manipulation of numbers, are especially valued. Thus, what defines OMB's methodology is not just the centrality of numbers but the importance of finance, accounting, and economic principles and the critical use of modeling techniques.

Because of OMB's institutional relationship to other agencies, it can effectively impose this methodology on other agencies. In this sense, OMB's is a "hegemonic methodology." a way of arriving at decisions that dominates, if not eliminates, other possible approaches. To maximize an agency's funding chances, the value of proposed new programs or changes to existing programs ought to be numerically justified, using a statistical or mathematical model based on principles or ideas from ac-

6. This is similar to the relationship between the federal OMB and presidential power (Wood and Waterman 1991: 804-805). 
counting, finance, or economics. Using such a methodology is a first line of offense and establishes an agency's credibility and legitimacy in its arguments with $\mathrm{OMB}$.

One example of OMB's methodological hegemony was the conflict inside the New York City government over how much a permanent housing program would reduce the homeless shelter population. Because hundreds of millions of dollars was at stake, OMB, HRA, and the Mayor's Office met to decide the issue. OMB and HRA each came with their required mathematical and statistical models. Without these, it is unlikely HRA could have secured such a meeting; it would have lost the issue at lower levels of the decision-making process. But each agency had very divergent estimates-concrete fictions-of the shelter bed turnover rate that was critical to the program effects each model estimated. That each agency had no good data to support its estimate of this statistic was not seriously addressed; most of the discussion was about the conflicting impacts on the shelter population that the models gave. OMB showed that the housing program would drastically decrease the shelter population; HRA showed it would cause a small decline. ${ }^{7}$ Responding to HRA, OMB's director objected to spending large sums of money for a program that would not cause a large decrease in the shelter population. That is, he took as the only goal something that was numerically defineable and responsive to modeling - the shelter population. HRA's rejoinder was a general social welfare argument: that providing permanent housing was worth doing because it would house many homeless people and improve their lives even if the shelter population did not decrease much. But HRA's models could not show these outcomes, because they could only model the shelter population. The response from OMB's director was right on cue, "Of course you have to make the social welfare argument." That is, HRA was talking about the well-being of homeless people in general and did not have a model showing numerical results. So, from the perspective of the hegemonic methodology (in the person of the OMB director), it was forced into making a nonnumerical and, hence, less powerful argument.

7. One might think that OMB would try to show that the program would not work very well and that HRA would try to show that it would. But OMB wanted to cut other parts of HRA's budget, contingent on its showing the disputed program to be highly effective, and HRA was trying to prevent these cuts. 


\section{Problems with the OMB Approach}

There are many problems with OMB's approach. ${ }^{8}$ The ones I wish to discuss are how it emphasizes manipulating numbers but ignores the questions of what the numbers measure and, more fundamentally, whether numbers are the correct way to think about understanding some phenomenon. OMB overemphasizes modeling to the detriment of measurement, and some benefits just cannot be captured by counting but are not any the less important.

The usefulness of any count depends critically on the conceptualization of what that count is a count of and on how well the count is carried out: in short, on validity and reliability. OMB modelers are not as conscious about these issues as they are, say, about problems of model assumptions or of particular calculation techniques. ${ }^{9}$ As a result, for example, an elaborate OMB five-year model for dealing with the problem of homeless adults, on which at least one person-year of time had been spent, was scrapped when people who did think about measurement (not OMB) demonstrated that OMB's numbers were not valid. Discussions with OMB tend to be about how the model works, not how valid or reliable the numbers are.

A second problem with this methodology is that some things are just hard to translate into a count. This might be particularly true in social welfare, where improvement in the quality of life is a key outcome but which can be very hard to measure. ${ }^{10}$

Moreover, perhaps there are important outcomes that simply cannot be counted at all. Again, this may be particularly true in social welfare policy, whose goals are to restore or to maintain intangible elements like the webs of kinship and friendship that ought to matter when making policy about homeless families. The word intangible conveys that whatever "it" is, it is not going to be disclosed in some integer. A homeless family, for example, may move from its neighborhood into a shelter

8. Stone (1988) discusses extensively the many problems in policy-making of modeling methodologies.

9. Apparently, their training either causes or abets this problem. A former HRA colleague, a graduate of Harvard's Kennedy School who was a teaching assistant in a statistics course (i.e., she is mechodologically adept), complained that she was taught well how to create and manipulate models, but no one told her how to get good numbers in the first place.

10. We encounter this problem in other fields where numerical measurement is not easy. For example, how do we count damage to the environment in order to include that damage as a production cost (Tietenberg 1991)? 
and then to a government-allocated apartment in another part of town. Can we measure the cost (or profit) to the city of moving a family away from family and friends, from familiar surroundings, or from the schools, churches, and other institutions to which they were socially and emotionally attached?" Unlike my previous critique, this objection amounts to a rejection of OMB's methodology, because it states that there are ways of knowing apart from counting and modeling that are just as valid and that should be followed in policy-making. ${ }^{2}$

\section{The Impact of a Hegemonic Methodology}

At least four areas feel the impact of OMB's methodological hegemony. ${ }^{13}$ One is the kind of things researchers in government do; another is the goal of policy-making; a third is the creation of discrepancies between the expectations of the public and the government; and fourth is interest representation.

Because of OMB's methodology, agencies create staffs which tend to do a certain kind of research, one that is based on numbers and models, so as to arm the agency in its battles with OMB. Consider New York's five-year plans for the homeless. Although originally mandated by the city council, the plans became important for getting money committed to the homeless problem. The kinds of things one needed to know to carry out the modeling for the plan strongly affected what was researched. Concrete fictions are fictional, in part, because the needed information does not

11. On the importance of kinship relations in homelessness, see Rossi (n.d.). A study of families who left New York City shelters to housing that they, not the government, had found showed that a majority returned to the same neighborhoods, even the same addresses, that they had left to enter the shelters (Levy 1989: 6). This suggests that families want to live in areas with which they are familiar. (There are other explanations, which do not require such an interest: the families had no other option but to return to the homes they had left, or, since their contacts for learning about new housing are likely to live in their fomer neighborhoods and these contacts will know most about housing in that area, families will most probably return to their old neighborhood, even if they preferred to live elsewhere.)

12. Midgley (1991: 22) expresses the point well: "There is no single, infallible form of knowledge, forming a standard against which all others must be measured and by whose help they will all finally be made impregnable. Instead, there are many different ways of knowing, each with their [sic] own standards and their own suitable kinds of evidence."

13. The concept of hegemonic methodology has a wider application than just to OMB's methodology. And the conditions for a methodology to become hegemonic can be different from those in this case. Within HRA, for example, the hegemonic methodology was that of social work. By contrast with, say, the OMB methodology, the HRA's tends to focus on individual persons or families as the policy-affected unit, not counts of these people; to pay attention to concrete conditions in problem solving, rather than abstract principles; and to be particularistic in policy formation, rather than universalistic. 
exist. Thus, the five-year plans became the documents driving homeless research. ${ }^{14}$

In some sense, this is as it should be. We want government to research what it is doing or plans to do in dealing with homelessness. On the other hand, because it uses numbers-based modeling, it tends to ignore useful program ideas as well as crucial real world conditions that cannot be evaluated in models. This is especially true with problems such as homelessness, which is relatively nascent (at least in its "newer" form) and encompasses problems other than just lack of housing, and where policy failure is more common than success.

The second impact of OMB's methodology is to make changes in numbers the goal of policy, perhaps at the expense of unmeasured "qualitative" effects. This causes the numbers themselves to be interpreted as the problem, a form of reification.

The danger in formulating policies to change numbers is evident in education, when we train students how to take tests rather than how to think. To the extent that tests only measure the ability to take tests, positive changes in scores will not reflect a successful educational system, that is, one which teaches students how to think, though we may believe they do. ${ }^{15}$

The same problem is found in social welfare policies that focus on moving numbers in a "positive" direction, for example, by reducing the population in city homeless shelters, rather than trying to end homelessness. If the number given for the sheiter population measured homelessness, then reducing this number would indicate that the problem of poor people without homes was being solved. To the extent the number does not actually measure homelessness, policies aimed at changing the number, even if successful, will have less of an impact on the problem.

But worse, we will think we are ending homelessness. For many people in New York City government, the homeless problem was synonymous with the number of people in the shelters, and the way to resolve the problem was synonymous with running accounting models that showed how this number would decline.

For instance, my first reading of New York City's five-year plan dis-

14. The five-year plans did not drive all research projects, though there was a tendency in this direction.

15. This and the homeless example I am about to give simply demonstrate the policy implications of the kind of thinking that Peter Medawar described as being "on all fours with saying that a patient's temperature is his health or that the time he takes to nun a mile is his degree of athleticism" (Medawar 1982: 12). 
tressed me, because it did not deal with the fullness of the homeless problem I encountered every day on New York's streets. How aware were my colleagues, who put this document together, that it did not bear the strongest relationship to the street reality of the problem? Quite aware, it turns out, but the constraints of the hegemonic methodology, the administration's political conservatism, and a fiscal interest in decreasing the city budget combined to make them deal with only a piece of the problem. But this piece necessarily became the whole problem, as daily business transactions centered about what was happening to the numbers and how well the plan was being met. The reification of numbers as the problem was too seductive to resist.

A third impact of OMB's methodological hegemony is that focusing attention on the wrong thing, or, at least, not the whole thing, leads to differences between the expectations of the government and the public. Having defined numbers as the problem, government officials tend to believe that when the numbers improve, the situation is getting better, even though it may not, in reality, have improved much or at all. From their daily experiences, the public will probably know this, and an adversarial media will certainly emphasize that the situation has not improved. The result is a discrepancy between what the government thinks it has accomplished after much hard work and a lot of money and what the citizenry thinks of government's ability to solve problems. Officials become perplexed or belligerent, and citizens become distrusting or angry.

Policy-making for New York City's homeless families provides an example. From June 1988 to June 1990 , the number of sheltered homeless families declined by almost $\mathbf{4 0}$ percent and the Dickensian "welfare hotels" were almost emptied. City officials took great pride in this accomplishment, they themselves almost astonished at their success in changing the direction of numbers that had been rising for almost a decade.

However, the public, especially the media and homeless advocates, focused on other homeless families: the hundred thousand families who are doubled-up with relatives and friends, or the thousands who live in substandard housing. To city officials, you can't win for trying; to those outside government, government can't do anything right. ${ }^{16}$

16. Something similar occurred in New York City's attempt to improve its subways in the 1980s. After years of multibillion dollar capital expenditures, tremendous institutional reorganization, and hard work, the Metropolitan Transit Authority reported great improvement in the subways: the number of graffiti-free cars, the number of cars with all lights and all doors working. the number of new cars, and so forth. Imagine the authority's frustration when a survey it commissioned showed the public did not see that the subways had improved. 
Part of the explanation for this mutual enmity is a government focused on numbers that, at best, addressed only part of the problem. It was not that city government was wrong, for the decline in the shelter population was sought by everyone, but that its focus on numbers caused officials to ignore or play down those parts of the problem the numbers did not capture. The problem is broader and deeper than the shelter numbers can convey. This is what those outside government tend to see. Mistrust in government and a belief that government is inept result.

Finally, as we just saw, the prevailing hegemonic methodology has an impact on the representation of interests in policy-making. Hugh Heclo (1974: 305) has written that "[g]overnments puzzle as well as 'power'," but the form of that puzzling can affect for whom governments power. Creating models that define the homeless family problem as the need to empty shelters suggests that, once the shelters are empty, the need of very poor families for adequate housing will not be on the government's agenda. When that happens, there will be no policies addressing other aspects of the problem, such as doubled- and tripled-up households, substandard housing, or inadequate incomes.

Further, to the exent that a methodology cannot represent certain interests, these interests may find another methodology to use. For the homeless, this has usually meant the methodology of law, as advocates file suits to represent clients who have problems not adequately addressed by models, by five-year plans, or, more generally, by the government's will or ability (Kirschheimer 1989-90). This is not to say that other methods work any better to resolve the problem. In New York City, for example, the clash between legal methods and modeling has resulted in chaos, frustration, and a worsening problem. This result is due, in part, to the inadequacy of legal reasoning and to fundamental incongruities between the two approaches. ${ }^{17}$

This paper is not arguing that, in making policy, numbers and modeling are useless or that OMB's methodology is "another form of poetry" (Stone 1988). It is an argument for paying much greater attention to measurement and to the assumptions that are a model's foundation. I want to say with Midgley (see footnote 12) that there are different ways of knowing, and ways other than OMB's should be a part of policy-making.

17. Other factors and methodologies also help explain homeless policy-making in New York City. Surely, fiscal problems, ideological conservatism, administrative constraints, and institutional and electoral politics have also been important. 


\section{References}

Grinker, W. 1989. Progress Report on Five-Year Plan for Housing and Assisting Homeless Families. New York: Human Resources Administration.

Heclo, H. 1974. Modern Social Politics in Britain and Sweden. New Haven, CT: Yale University Press.

Kirschheimer, D. W. 1989-90. Sheltering the Homeless in New York City: Expansion in an Era of Government Contraction. Political Science Quarterly 104:607-23.

Levy, D. 1989. Families Who Exit HRA Emergency Housing: Preliminary Research Findings. New York: Human Resources Administration, Office of Policy and Program Development.

Medawar, P. 1982. Pluto's Republic. New York: Oxford University Press.

Midgley, M. 1991. Can't We Make Moral Judgments? New York: St. Martin's.

New York State Department of Social Services. 1990. The Homelessness Prevention Program: Outcomes and Effectiveness. Albany, NY: Office of Program Planning, Analysis and Development and Office of Shelter and Supported Housing Programs.

Rossi, P. H. n.d. The Family, Welfare, and Homelessness. Discussion Paper No. 037. Chapin Hall Center for Children, University of Chicago.

Stone, D. 1988. Policy Paradox and Political Reason. Glenview, L: Scott, Foresman. Tietenberg, T. H. 1991. Preserving the Global Environment. In Ecology Economics, Ethics: The Broken Circle, ed. F. Herbert Bormann and Stephen R. Kellert. New Haven, CT: Yale University Press.

Wood, B. D., and R. Waterman. 1991. The Dynamics of Political Control of the Bureaucracy. American Political Science Review 85:801-28. 